\title{
Tribological properties of a B2-type Al-Pd-Mn quasicrystal approximant
}

\author{
Chris Mancinelli \\ Department of Chemical Engineering, Carnegie Mellon University, Pittsburgh, Pennsylvania 15213 \\ Cynthia J. Jenks and Patricia A. Thiel \\ Department of Chemistry and Ames Laboratory, Iowa State University, Ames, Iowa 50011 \\ Andrew J. Gellman ${ }^{\text {a) }}$ \\ Department of Chemical Engineering, Carnegie Mellon University, Pittsburgh, Pennsylvania 15213
}

(Received 17 February 2003; accepted 24 March 2003)

\begin{abstract}
The tribological properties of a B2-type Al-Pd-Mn quasicrystal approximant were investigated and compared with those of an Al-Pd-Mn icosahedral quasicrystal. The approximant was of the $\beta$ phase, having a crystalline $\mathrm{CsCl}$-type structure and nominal composition $\mathrm{Al}_{48} \mathrm{Pd}_{42} \mathrm{Mn}_{10}$. Friction coefficients measured in ultrahigh vacuum between a pair of $\mathrm{Al}_{48} \mathrm{Pd}_{42} \mathrm{Mn}_{10}$ samples having truly clean surfaces were found to be twice as high as those reported for the $\mathrm{Al}_{70} \mathrm{Pd}_{21} \mathrm{Mn}_{9}$ quasicrystal. When the surfaces were oxidized by exposure to $\mathrm{O}_{2}$ or $\mathrm{H}_{2} \mathrm{O}$, the friction coefficients decreased by roughly a factor of two for both materials but the friction coefficient for the approximant remained roughly twice that of the quasicrystal. The rate of oxidation of the approximant was found to be one order of magnitude higher than that of the quasicrystal. This corroborates findings that suggest that quasicrystals exhibit an inherent resistance to oxidation and corrosion. Vickers hardness measurements show that the quasicrystal is roughly three times as hard as the approximant.
\end{abstract}

\section{INTRODUCTION}

Quasicrystalline materials have been studied extensively since their discovery over 20 years ago, yet much debate remains as to the origins of their desirable materials properties. These desirable properties reportedly include low friction, high hardness, high wear and corrosion resistance, and low surface energy. ${ }^{1-14}$ Quasicrystals were also found to have low thermal conductivity and moderate electrical conductivity, making them suitable for use in thermoelectric devices. ${ }^{1,15-18}$ There are, however, some limits to their potential for commercial use due, in part, to their brittle nature. As a result, the properties of quasicrystalline thin films are also being thoroughly examined since it seems that this is the first form in which they are likely to achieve widespread commercial application. Despite this extensive work, the fundamental question of whether or not the desirable properties of quasicrystals are a direct result of quasicrystallinity remains unclear.

\footnotetext{
a) Address all correspondence to this author. e-mail: ag4b@andrew.cmu.edu
}

Quasicrystals are metallic alloys that typically exist over a narrow region of the compositional phase diagram. The quasicrystalline phases are surrounded by related crystalline phases called approximants. The approximant phases, though crystalline, are related to the parent quasicrystal both structurally and electronically. Thus, one would expect the approximants to have materials properties similar to those of the quasicrystals. These approximant phases indeed play a role in the tribology of the quasicrystals as demonstrated by Dong et al., who showed that one of the deformation mechanisms during scratching of an $\mathrm{AlCuFe}$ quasicrystal is a stressinduced phase transition, leading to formation of a bodycentered cubic phase, or disordered $\beta$ phase. ${ }^{19,20}$ In this paper, we report a comparison between the tribological properties of an Al-Pd-Mn quasicrystal and one of its $\beta$-phase crystalline approximants, having a $\mathrm{CsCl}$ structure. Although it has a bulk crystalline structure, the $\beta$ phase is deemed to be a quasicrystal approximant on the basis of its valence electron density per atom, $e / a$. Within this definition approximants must have an $e / a$ value close to that of the parent quasicrystal. ${ }^{21}$ This implies that they have similar electronic structures, although their crystal structures are different. In any ternary phase diagram, a constant $e / a$ value defines a 
compositional line along which it is possible to have a series of approximants with quite different compositions. $^{22}$

From a tribological viewpoint, the origin of the low friction properties of quasicrystals is an intriguing problem for which a number of ideas have been proposed. Quasicrystals are metallic alloys having unconventional crystallographic symmetry elements such as 5-, 8-, 10-, or 12-fold rotation axes and possessing long-range order without the translational periodicity normally associated with crystalline solids. The inherent lack of translational periodicity results in incommensurate interfaces between quasicrystalline and crystalline materials. Under some conditions this incommensurability may be associated with low friction. ${ }^{23,24}$ The influence of commensurability on friction has been examined by a number of experimental and theoretical studies. ${ }^{25,26}$ It has been observed that friction becomes negligible for incommensurate surfaces sliding under conditions of elastic contact. If some contamination or adsorbed layer is present at the interface, however, the surfaces can be pinned together and effects of commensurability will not be observed. Under typical sliding conditions, however, plastic deformation almost always occurs. One suggestion for a mechanism leading to low friction under conditions of plastic deformation is that the $\mathrm{Al}_{2} \mathrm{O}_{3}$ overlayers on quasicrystals delaminate leading to slip. The $\mathrm{Al}_{2} \mathrm{O}_{3}$ layers are weakly adherent to the substrate and delaminate under shear resulting in low friction and wear of the sacrificial $\mathrm{Al}_{2} \mathrm{O}_{3}$ layers. ${ }^{27}$ Quasicrystals are also known to be hard materials, and correlations between friction and hardness suggest that low friction occurs in hard materials. ${ }^{1,15,28,29}$ Yet another interesting idea relates low friction and surface energy to the extremely low density of $\mathrm{Al} 3 p$ states at the Fermi level of quasicrystals. ${ }^{30}$ In summary, there are a number of suggested mechanisms for the nominally low friction properties of quasicrystals; however, they lack direct and conclusive experimental verification.

While there are many different possible factors contributing to the low friction of quasicrystals, it is difficult to identify one as the most critical. It is also a challenge to design and conduct an experiment under well-defined conditions that can effectively probe the tribological properties of quasicrystals and prove or disprove different hypotheses for the origins of low friction. The use of well-defined conditions is always an issue in the discussion of tribological phenomena since these are inherently surface-related properties and are extremely sensitive to the presence of surface contamination. Another hurdle to any experimental test of the connection between quasicrystallinity and tribological properties is that it is impossible to experimentally vary the relevant parameters independently and some parameters cannot be varied continuously. For example, structure and composition of the alloys cannot be varied independently and structure cannot, of course, be varied continuously. While the composition of an alloy may be varied continuously, its structure is often dictated by a phase diagram that does not allow variation in a continuous manner. As a result of these numerous problems, it is difficult to perform reliable measurements that allow one to make unambiguous statements about the role of quasicrystallinity in the determination of macroscopic materials properties such as friction.

The goal of the measurements described in this paper has been to relate the friction and oxidation properties of quasicrystal and approximant surfaces to their structure. Needless to say, despite our best efforts, we do not surmount all the problems mentioned in the previous paragraph. In this investigation, we have used two materials. One is the icosahedral quasicrystal, $\mathrm{Al}_{70} \mathrm{Pd}_{21} \mathrm{Mn}_{9}$, and the other is its $\beta$ phase (or $\mathrm{B} 2$ phase) approximant, $\mathrm{Al}_{48} \mathrm{Pd}_{42} \mathrm{Mn}_{10}$, which has a cubic CsCl-type structure. The Al-Pd-Mn system is very complex, and several efforts have been made to discern the regions of the phase diagram which contain the quasicrystals and their approximants. ${ }^{31-33}$ The stable icosahedral quasicrystalline phase was found to exist at a composition of $\mathrm{Al}_{70.3} \mathrm{Pd}_{21.4} \mathrm{Mn}_{8}{ }^{34} \mathrm{In}$ reality, it exists over a narrow range of compositions of each of its components. Surrounding the quasicrystalline region in the phase diagram are several approximant phases containing various crystalline structures, many of which have been identified. ${ }^{31-34}$ The $\mathrm{Al}_{48} \mathrm{Pd}_{42} \mathrm{Mn}_{10}$ approximant used in this study is an approximant phase that exists over a rather large region of the Al-Pd-Mn phase diagram. It is a B2-type approximant phase (usually named $\beta$ phase) having a $\mathrm{CsCl}$ cubic structure and a well-defined orientation relationship with the quasicrystal, as do other frequently encountered approximant phases. ${ }^{19,22,35}$ In summary, while we have kept the alloy composition of the approximant as close to that of the quasicrystal as possible, we still have two samples with distinct crystallography.

One of the virtues of the measurements reported in this paper is that they are performed under the well-defined and controlled conditions of ultrahigh vacuum (UHV). In all cases, the surfaces of the quasicrystal and the approximant alloy were prepared and cleaned using stateof-the-art surface science methods. Furthermore, the measurements of friction and surface oxidation have all been performed in UHV without exposure of the surfaces to any form of contamination. The results of these measurements reveal that the friction between pairs of the approximant surfaces is always higher than that measured between pairs of the quasicrystal surfaces. Furthermore, the oxidation rates of the approximant alloy are significantly higher than those of the quasicrystal. Although the cause of these differences is not fully understood, the results of these measurements serve as reliable starting points for discussion of quasicrystal friction and oxidation. 


\section{EXPERIMENTAL}

All the experiments to be described in this report were performed in a stainless steel UHV chamber with a base pressure below $10^{-10}$ torr. The chamber was fitted with a variety of instruments to accommodate in situ surface preparation and analysis of the samples. These included a quadrupole mass spectrometer, a four-grid retarding field analyzer (RFA) for low-energy electron diffraction (LEED), an $\mathrm{Ar}^{+}$ion sputter gun for surface cleaning, leak valves to introduce gases into the chamber, a field emission electron gun used in conjunction with a secondary electron detector for scanning electron microscopy (SEM), and a concentric hemispherical analyzer (CHA) for Auger electron spectroscopy (AES). For the previous study using the $\mathrm{Al}_{70} \mathrm{Pd}_{21} \mathrm{Mn}_{9}$ quasicrystals, the RFA and LEED optics were used for AES measurements. ${ }^{36}$ Subsequent AES measurements of the $\mathrm{Al}_{48} \mathrm{Pd}_{42} \mathrm{Mn}_{10}$ approximants were performed using the CHA. In addition to these instruments, the chamber was equipped with a unique device for the measurement of friction between pairs of highly characterized surfaces, both of which were subjected to the same preparation and analysis procedures.

All the samples used in this study were made at the Ames Laboratory at Iowa State University and were approximately $10 \times 10 \times 2 \mathrm{~mm}$ thick. The two $\mathrm{Al}_{70} \mathrm{Pd}_{21} \mathrm{Mn}_{9}$ quasicrystals were single grains oriented to expose the fivefold symmetric rotation axis normal to the surface. The two $\mathrm{Al}_{48} \mathrm{Pd}_{42} \mathrm{Mn}_{10}$ approximants were polycrystalline with several large grains near the center of the sample and many smaller grains at the sample edges and corners. All samples were mechanically polished with $0.050-\mu \mathrm{m}$ alumina paste prior to sample mounting. One sample from each set was polished with a slight spherical curvature (radius approximately $13 \mathrm{~cm}$ ) to ensure contact at or near the center of the samples and not at the edges. In this way, a sphere-on-flat contact configuration was approximated with contact areas on the order of microns as observed using SEM.

A pair of identical samples were mounted in the chamber at any one time to allow friction measurements between them. The curved sample was fixed in a sample holder and mounted on a manipulator capable of motion in the $x, y$, and $z$ (vertical) directions as well as rotation about the vertical axis of the chamber. Quasicrystals are poor electrical conductors and as such could not be spot welded directly to the sample holder. Instead, the samples were firmly secured against a Ta plate through the use of $\mathrm{Pd} / \mathrm{Ag}$ leaf springs, which were spot welded to the plate. The plate was then spot welded to Ta wires, which were clamped to the sample holder. This assembly was then mounted on the manipulator so that good electrical contact was achieved. The sample could be heated resistively to $T>800 \mathrm{~K}$ and cooled to $T<100 \mathrm{~K}$ through mechanical contact with a liquid-nitrogen reservoir. The temperature of the sample was measured using a K-type thermocouple spot welded to the Ta backing plate.

The flat sample of each pair was mounted to the friction measuring device, or UHV tribometer. The following description of the UHV tribometer will be short, as specific details of the device were reported previously. ${ }^{37}$ The flat sample was first firmly attached to a Ta plate using $\mathrm{Pd} / \mathrm{Ag}$ leaf springs. The plate was spot welded to Ta wires, which were clamped to a $\mathrm{Cu}$ frame. The frame was clamped to a $\mathrm{Cu} / \mathrm{Be}$ sheet spring onto which eight strain gauges are bonded. These strain gauges allow simultaneous measurement of both normal and shear forces when the curved manipulator sample is brought into contact with, and sheared relative to, the flat tribometer sample. The sample can be heated to $T>800 \mathrm{~K}$ through electron bombardment by a filament located behind the sample and cooled to $T<120 \mathrm{~K}$ through mechanical contact with a liquid-nitrogen reservoir. The temperature of the sample was measured using a K-type thermocouple spot welded to the Ta backing plate.

The UHV tribometer is a force transducer and was calibrated outside the chamber using weights of known mass. The response of both shear and normal forces were independently measured and found to be linear in the applied force over the calibration range of $5-250 \mathrm{mN}$. Once inside the chamber, the samples were aligned optically to ensure their surface normals were parallel to each other. They were also positioned so that the sliding motion of the manipulator sample was parallel to the surface of the tribometer sample. The friction experiment was then performed by first bringing the samples into contact with one another under a normal load of $F_{\mathrm{N}} \cong$ $40 \mathrm{mN}$ and then shearing at a constant speed of $v_{\mathrm{s}}=$ $20 \mu \mathrm{m} / \mathrm{s}$ using motorized micrometers. Normal and shear forces were simultaneously measured over the sliding distances of 300 to $600 \mu \mathrm{m}$. The samples were then separated and the manipulator sample moved slightly by a rotation of $\pm \sim 1.5^{\circ}$ from the normal and by raising or lowering of the sample along the $z$ axis by $\pm \sim 2 \mathrm{~mm}$ before making another contact. This is to ensure that each friction measurement uses different parts of the surfaces.

All samples were given the same surface cleaning treatment prior to any friction measurements. Initial cleaning consisted of several cycles of $\mathrm{Ar}^{+}$ion bombardment and annealing. The primary surface contaminant was oxygen, which continuously diffused from the bulk to the surface where it was removed by $\mathrm{Ar}^{+}$sputtering until the bulk was depleted to the point that annealing at $800 \mathrm{~K}$ or higher no longer resulted in the appearance of oxygen at the surface as determined by AES. Friction measurements were made between clean surfaces and between surfaces modified by exposure to extra dry oxygen (Matheson Gas Products, Montgomeryville, PA) or purified $\mathrm{H}_{2} \mathrm{O}$. The exposures were performed by filling 
the chamber with gas or vapor. Exposures are reported in units of Langmuirs ( $1 \mathrm{~L}=10^{-6}$ torr s) with the pressure uncorrected for ion gauge sensitivity.

The hardness of both the quasicrystal and approximant was measured using an "LL" Tukon microhardness tester (Canton, MA) and a diamond Vickers indenter with loads of $0.4 \mathrm{~kg}$ for the $\mathrm{Al}_{70} \mathrm{Pd}_{21} \mathrm{Mn}_{9}$ quasicrystal and $0.3 \mathrm{~kg}$ for the $\mathrm{Al}_{48} \mathrm{Pd}_{42} \mathrm{Mn}_{10}$ approximant. A typical identation depth was approximately $4.3 \mu \mathrm{m}$ for the $\mathrm{Al}_{70} \mathrm{Pd}_{21} \mathrm{Mn}_{9}$ quasicrystal and $6.5 \mu \mathrm{m}$ for the $\mathrm{Al}_{48} \mathrm{Pd}_{42} \mathrm{Mn}_{10}$ approximant.

\section{RESULTS AND DISCUSSION}

\section{A. Oxidation}

Any metal or alloy exposed to air is susceptible to oxidation of its surface. Such a change in the nature of the metal surface will affect the properties of that metal, and any material that resists oxidation has potentially useful engineering applications. Quasicrystals are such materials, and many studies have been performed which lend insight into the mechanism of their surface oxidation. It is well understood that exposure of clean Al-rich quasicrystals (AlPdMn or $\mathrm{AlCuFe}$ ) to oxygen results in the selective oxidation of $\mathrm{Al}$ to form a thin and passivating $\mathrm{Al}_{2} \mathrm{O}_{3}$ layer. ${ }^{6-9,11-14,38,39}$ This layer acts as a barrier to further oxidation of the bulk. Exposure to $\mathrm{H}_{2} \mathrm{O}$ (vapor or liquid), however, has been shown to increase the oxide layer thickness beyond that reached by oxidation in $\mathrm{O}_{2}{ }^{11}$ As in the case of the $\mathrm{Al}_{70} \mathrm{Pd}_{21} \mathrm{Mn}_{9}$ quasicrystal, exposure of the $\mathrm{Al}_{48} \mathrm{Pd}_{42} \mathrm{Mn}_{10}$ quasicrystal approximant phase to oxygen has been shown to selectively oxidize the $\mathrm{Al}$ to form a layer of $\mathrm{Al}_{2} \mathrm{O}_{3}$. This does not, however, form the same protective layer as on the quasicrystal surface in the sense that $\mathrm{Mn}$ and possibly Pd are oxidized as well. ${ }^{11,40}$

We have studied the oxidation of the clean surface of the $\mathrm{Al}_{48} \mathrm{Pd}_{42} \mathrm{Mn}_{10}$ approximant and compared the oxygen uptake curve to the results of our prior measurements of the oxidation of the $\mathrm{Al}_{70} \mathrm{Pd}_{21} \mathrm{Mn}_{9}$ quasicrystal surface. AES was used to monitor the uptake of oxygen on the surface of the samples during exposure to dry oxygen followed by exposure to $\mathrm{H}_{2} \mathrm{O}$ vapor. Figure 1 shows Auger spectra for the clean $\mathrm{Al}_{48} \mathrm{Pd}_{42} \mathrm{Mn}_{10}$ approximant surface and those of the surface after exposure to $\mathrm{O}_{2}$ and $\mathrm{H}_{2} \mathrm{O}$ vapor. Similar Auger spectra have been reported previously for the quasicrystal surface. ${ }^{36}$ The spectrum of the clean surface reveals the peaks for each element in the alloy at the expected energies $(\mathrm{Mn}, 40 \mathrm{eV}$; Al, $68 \mathrm{eV}$; $\mathrm{Pd}, 330 \mathrm{eV})$. The spectral feature for $\mathrm{Al}$ is sharp and at the appropriate energy for metallic $\mathrm{Al}^{0}$, which, in the absence of the oxygen peak, is a good indication that the sample is devoid of surface oxidation. Exposure of the surface to $\mathrm{O}_{2}$ at $300 \mathrm{~K}$ for a total of $320 \mathrm{~L}$ $\left(1 \mathrm{~L}=10^{-6}\right.$ torr s) results in the adsorption of oxygen as revealed by the middle spectrum of Fig. 1 showing the

\section{AES - Clean \& Oxidized $\mathrm{Al}_{48} \mathrm{Pd}_{42} \mathrm{Mn}_{10}$ $\mathrm{O}_{2} \& \mathrm{H}_{2} \mathrm{O}$ Exposure at $300 \mathrm{~K}$}

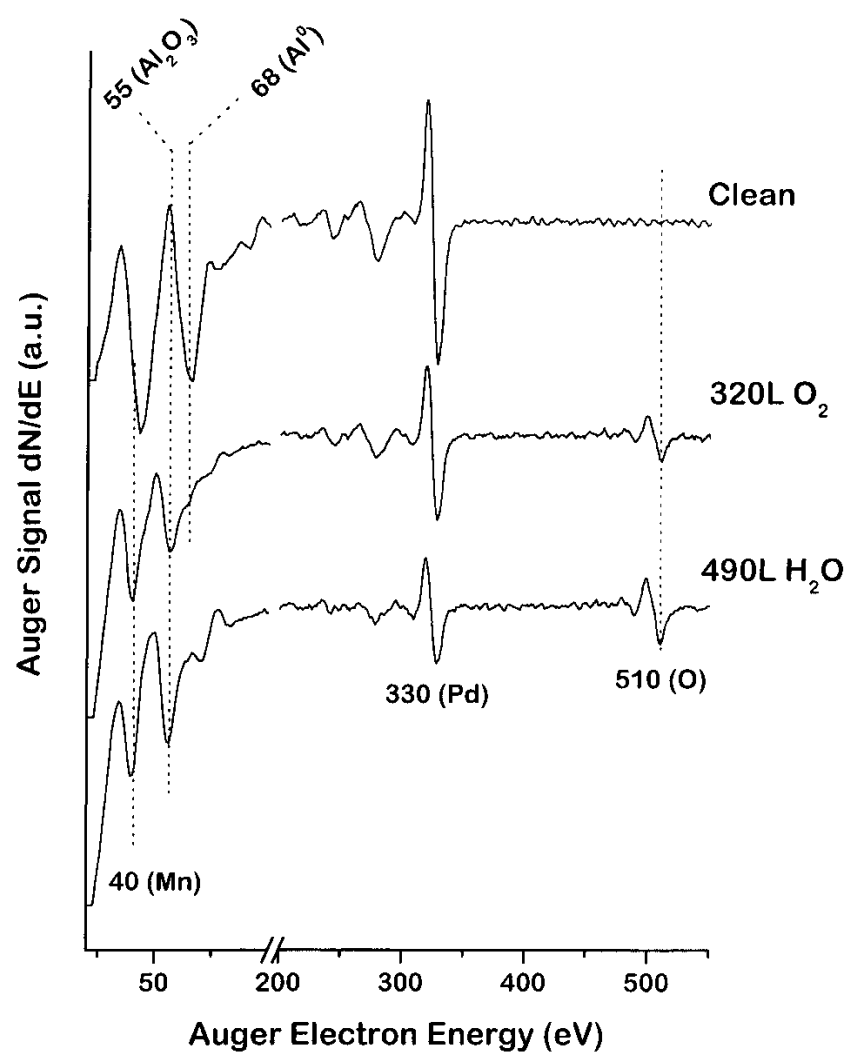

FIG. 1. Auger electron spectra of the clean $\mathrm{Al}_{48} \mathrm{Pd}_{42} \mathrm{Mn}_{10}$ surface (top) and the same surface following saturation exposures of $\mathrm{O}_{2}$ and $\mathrm{H}_{2} \mathrm{O}$ vapor. The clean surface spectrum exhibits peaks from the three components of the alloy: $\mathrm{Al}$ at $68 \mathrm{eV}, \mathrm{Pd}$ at $330 \mathrm{eV}$, and $\mathrm{Mn}$ at $40 \mathrm{eV}$. Once oxidized a peak due to $\mathrm{O}$ appears at $510 \mathrm{eV}$. Also note that the $\mathrm{Al}$ peak shifts to $55 \mathrm{eV}$ as a result of the formation of a film of aluminum oxide.

emergence of the oxygen Auger peak at $510 \mathrm{eV}$. In addition, the metallic $\mathrm{Al}^{\circ}$ Auger feature at $68 \mathrm{eV}$ has shifted to $55 \mathrm{eV}$, the energy associated with $\mathrm{Al}^{3+}$ in $\mathrm{Al}_{2} \mathrm{O}_{3}$. This peak suggests that the $\mathrm{Al}$ in the near-surface region is almost fully converted to the oxide by oxidation with dry oxygen alone. This differs from the results of previous observations of the oxidation of the $\mathrm{Al}_{70} \mathrm{Pd}_{21} \mathrm{Mn}_{9}$ quasicrystal in $\mathrm{O}_{2}$. In the case of the quasicrystal, exposure to $340 \mathrm{~L} \mathrm{O}_{2}$ at $300 \mathrm{~K}$ resulted in $\mathrm{Al}^{0}$ and $\mathrm{Al}^{3+}$ peaks of nearly equal intensity. ${ }^{36}$ This suggests that the quasicrystals have some degree of oxidation resistance in the sense that the saturation $\mathrm{Al}_{2} \mathrm{O}_{3}$ film thickness is lower on the quasicrystal than on the approximant. Further oxidation of the approximant surface was achieved by the introduction of $\mathrm{H}_{2} \mathrm{O}$ into the chamber as shown in the bottom spectrum of Fig. 1. In this final spectrum, the $\mathrm{O}$ peak at $510 \mathrm{eV}$ increases, while the $\mathrm{Mn}$ and $\mathrm{Pd}$ peaks decrease. Metallic $\mathrm{Al}^{0}$ is also completely converted to $\mathrm{Al}_{2} \mathrm{O}_{3}$ after 
exposure to $\mathrm{H}_{2} \mathrm{O}$ vapor. These observations are in qualitative agreement with the corresponding Auger spectrum for the quasicrystal.

The oxidation kinetics of the $\mathrm{Al}_{48} \mathrm{Pd}_{42} \mathrm{Mn}_{10}$ approximant have been studied by monitoring the uptake of oxygen by the surface during exposure to $\mathrm{O}_{2}$. Figure 2 shows the intensity of the $\mathrm{O}_{510}$ Auger electron signal on the $\mathrm{Al}_{48} \mathrm{Pd}_{42} \mathrm{Mn}_{10}$ approximant surface as a function of exposure to $\mathrm{O}_{2}$ gas and subsequent exposure to $\mathrm{H}_{2} \mathrm{O}$ vapor. The results of several different experiments are plotted, each one beginning with the atomically clean surface devoid of any oxide as determined by AES. The oxygen Auger peak intensity increases initially and then levels

\section{Oxygen Uptake on QC and Approximant}

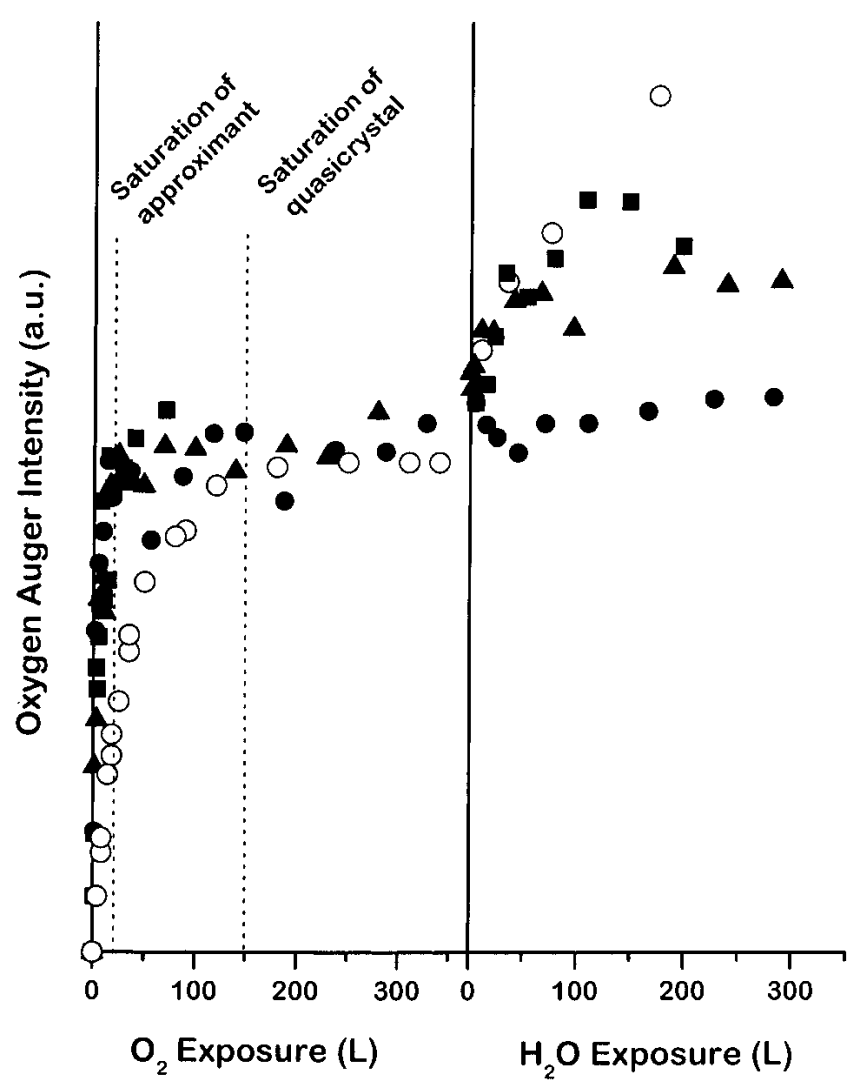

FIG. 2. Oxygen uptake on the $\mathrm{Al}_{70} \mathrm{Pd}_{21} \mathrm{Mn}_{9}$ quasicrystal (open circles) and the $\mathrm{Al}_{48} \mathrm{Pd}_{42} \mathrm{Mn}_{10}$ approximant (all filled symbols) surfaces as a function of exposure to $\mathrm{O}_{2}$ followed by exposure to $\mathrm{H}_{2} \mathrm{O}$ vapor. The exposure to $\mathrm{O}_{2}$ results in the formation of a thin film of aluminum oxide which passivates the surface against further oxidation by $\mathrm{O}_{2}$. Subsequent exposure to $\mathrm{H}_{2} \mathrm{O}$ vapor results in a thickening of the oxide film followed by passivation at a higher film thickness. The rate of oxidation of the $\mathrm{Al}_{48} \mathrm{Pd}_{42} \mathrm{Mn}_{10}$ approximant during initial exposure to $\mathrm{O}_{2}$ is roughly ten times greater than the initial rate of oxidation of the $\mathrm{Al}_{70} \mathrm{Pd}_{21} \mathrm{Mn}_{9}$ quasicrystal. Oxidation was performed with crystal temperatures of approximately $120 \mathrm{~K}$ and exposure pressures of $10^{-8}$ or $10^{-7}$ torr (for higher doses). off after an exposure of approximately $20 \mathrm{~L}$. This suggests that oxygen reacts with surface $\mathrm{Al}$ to form a thin passivating layer preventing further oxidation. Other studies have also observed the oxidation of $\mathrm{Mn}$ in the surface layers. ${ }^{11,40}$ More aggressive oxidizing environments including exposure to air and immersion in water have been shown to produce thicker oxide layers. ${ }^{11}$ In addition, oxidation is known to be a pressure dependent process ${ }^{41}$ with competition taking place between surface oxidation and oxygen diffusion into the bulk. Subsequent exposure of the surface to $\mathrm{H}_{2} \mathrm{O}$ vapor causes a slight increase in the oxide thickness, but that too saturates rather quickly at an exposure of roughly $50 \mathrm{~L}$. Figure 2 also shows previous measurements of uptake of oxygen on the $\mathrm{Al}_{70} \mathrm{Pd}_{21} \mathrm{Mn}_{9}$ quasicrystal (open circles). Since these measurements were taken with two different electron energy analyzers, the absolute peak heights are not directly comparable and have been scaled to give the same amplitude at saturation of the surface by exposure to $\mathrm{O}_{2}$. Qualitatively, these results are the same as those for the $\mathrm{Al}_{48} \mathrm{Pd}_{42} \mathrm{Mn}_{10}$ approximant. The rate of oxidation for the approximant, however, is roughly one order of magnitude greater than that of the quasicrystal. Where it requires an exposure of only $20 \mathrm{~L}$ to saturate the surface of the approximant with oxygen, it requires an exposure of approximately $150 \mathrm{~L}$ in the case of the quasicrystal. This indicates that with respect to the approximant the quasicrystal has some resistance to oxidation.

Both the $\mathrm{Al}_{70} \mathrm{Pd}_{21} \mathrm{Mn}_{9}$ quasicrystal and the $\mathrm{Al}_{48} \mathrm{Pd}_{42} \mathrm{Mn}_{10}$ approximant exhibit oxidation resistance in the sense that they both form an oxide layer, which passivates their surfaces and retards the uptake of further oxygen. The new and rather remarkable observation is that the rate of oxidation of the quasicrystal is roughly one order of magnitude lower than that of the approximant. Similar observations were made with the icosahedral $\mathrm{Al}_{63.4} \mathrm{Cu}_{24} \mathrm{Fe}_{12.5}$ quasicrystal and its approximants. ${ }^{38}$ Since $\mathrm{Al}$ is the most readily oxidized element in these Al-rich alloys, one might expect the quasicrystal to oxidize faster as it has a higher Al content than the approximant, yet this is not the case. The origins of this additional oxidation resistance of the quasicrystal are not yet well understood.

\section{B. Friction}

The friction between two materials is affected by many factors, one of which is, of course, the materials themselves. Our experiment uses two samples of the same material that are prepared under identical conditions in a well-controlled environment. In this way, we are able to investigate the differences between the frictional properties of pairs of $\mathrm{Al}_{70} \mathrm{Pd}_{21} \mathrm{Mn}_{9}$ quasicrystals and the $\mathrm{Al}_{48} \mathrm{Pd}_{42} \mathrm{Mn}_{10}$ approximants while controlling as many of the independent variables that influence friction 
as possible. The goal of this study is to address the question of whether the low friction of quasicrystals arises as a result of their unique aperiodic structure. In this regard, the ideal experiment would use pairs of approximants with physical and electronic properties identical to those of the quasicrystal. Unfortunately, this is not possible since compositional changes in the alloys must change their bulk properties. Therefore, a set of experiments must be performed using a wide range of alloy compositions that encompasses the quasicrystalline phase as well as several surrounding approximant phases. This study is one in such a set and is progress along the path to discovering the origins of low friction in quasicrystals.

Friction measurements between pairs of $\mathrm{Al}_{48} \mathrm{Pd}_{42} \mathrm{Mn}_{10}$ approximants that have been exposed to air and prior to any surface cleaning or preparation have yielded static friction coefficients of $\mu_{\mathrm{s}}=0.10 \pm 0.02$. The static friction coefficient $\left(\mu_{\mathrm{s}}\right)$, which will be reported throughout this paper, is defined as the shear force required to initiate sliding divided by the normal load. The dynamic, or steady state, friction coefficient $\left(\mu_{\mathrm{d}}\right)$ could equally well have been reported and would not change the overall conclusions of this report. In previous work, we measured friction coefficients of $\mu_{\mathrm{s}}=0.11 \pm 0.02$ between the air-exposed surfaces of $\mathrm{Al}_{70} \mathrm{Pd}_{21} \mathrm{Mn}_{9}$ quasicrystals prior to UHV cleaning. ${ }^{36}$ The friction coefficient of the air-exposed, contaminated approximant surfaces is indistinguishable from that of the quasicrystal. The advantage of performing friction experiments under UHV conditions is that the surfaces can be cleaned of contaminants, such as carbon, sulfur, and oxygen, and the true properties of the material can be examined. After extensive cleaning of the surfaces by several cycles of $\mathrm{Ar}^{+}$ion sputtering and annealing, a friction coefficient of $\mu_{\mathrm{s}}=$ $0.60 \pm 0.08$ was obtained between the $\mathrm{Al}_{70} \mathrm{Pd}_{21} \mathrm{Mn}_{9}$ quasicrystals. This is a clear indication that the low-friction coefficients measured between the air-exposed surfaces are not an inherent trait of the material. Similarly, friction measurements between truly clean $\mathrm{Al}_{48} \mathrm{Pd}_{42} \mathrm{Mn}_{10}$ approximants gave a friction coefficient of $\mu_{\mathrm{s}}=1.22$ \pm 0.85 , much higher than that of the air-exposed surfaces. Not only is this friction coefficient larger than that of the air-exposed surfaces, but also twice as large as the friction coefficient between the quasicrystal surfaces. Previous comparative friction studies of quasicrystals and their approximants have shown similar trends, although those experiments were conducted under atmospheric conditions and using sliders of different materials than the samples. ${ }^{19,29}$

Figure 3 shows three randomly chosen plots of singlepass friction measurements made between clean $\mathrm{Al}_{48} \mathrm{Pd}_{42} \mathrm{Mn}_{10}$ approximants. They show the shear and normal forces between the samples during sliding and reveal rather erratic sliding behavior. Cases of stick-slip friction were observed, as can easily be seen in the

\section{Friction - Clean Approximant $v_{\mathrm{s}}=20 \mu \mathrm{m} / \mathrm{sec}, \mathrm{T}=300 \mathrm{~K}$}



Time (sec)

FIG. 3. Shear and normal forces observed during three friction measurements made between clean $\mathrm{Al}_{48} \mathrm{Pd}_{42} \mathrm{Mn}_{10}$ approximant surfaces. The upper trace is a plot of the normal force, while the lower trace is a plot of the shear force. Friction between the approximants was found to be more erratic than for the quasicrystals. Adhesion (left trace) is indicated by a negative normal force upon surface separation. Stickslip friction was also observed for the approximants (middle trace). The conditions used for friction measurements were $F_{\mathrm{N}} \sim 20-50 \mathrm{mN}$, $v_{\mathrm{s}}=20 \mu \mathrm{m} / \mathrm{s}$, and $T=300 \mathrm{~K}$.

middle trace, and there were several instances of adhesion between the samples, as indicated in the first trace by the negative normal force upon sample separation. It is exactly these sliding phenomena that make the static friction coefficient a more useful comparator than the dynamic friction coefficient. The friction behavior for clean $\mathrm{Al}_{70} \mathrm{Pd}_{21} \mathrm{Mn}_{9}$ quasicrystals, however, was not so irregular, as can be seen in Fig. 4. Under similar sliding conditions, quasicrystal friction can be characterized as slip in nature. In addition, no cases of stick-slip or adhesion were observed during shearing of the quasicrystals. Most importantly, the friction coefficients measured between clean $\mathrm{Al}_{70} \mathrm{Pd}_{21} \mathrm{Mn}_{9}$ quasicrystals were lower than those between clean $\mathrm{Al}_{48} \mathrm{Pd}_{42} \mathrm{Mn}_{10}$ approximants.

Measuring friction between truly clean surfaces is the only way to investigate the intrinsic tribological properties of the materials themselves. Outside the UHV environment metal surfaces are always coated with an oxide 
layer. This oxidation is known to influence the friction between surfaces of quasicrystals. ${ }^{36} \mathrm{We}$ have performed friction experiments during oxidation of the approximant surfaces to determine how oxidation affects their tribological properties and to compare these effects with the effects of oxidation on the frictional properties of their quasicrystalline counterpart. The measured values of the friction coefficient as a function of the exposure of the approximant surfaces to $\mathrm{O}_{2}$ and then $\mathrm{H}_{2} \mathrm{O}$ are plotted in Fig. 5 (solid circles and squares) and compared with the previously measured values for the quasicrystals (open circles). Each point represents the average static friction coefficient measured from a set of at least 12 friction measurements. What is immediately apparent is that the friction coefficients of the approximants at all levels of oxidation are always higher than those of the quasicrystals. In fact, they are roughly twice as high in all instances. Oxidation of the approximants by exposure to oxygen alone passivates their surfaces and reduces the

\section{Friction - Clean Quasicrystal}

$$
v_{s}=20 \mu \mathrm{m} / \mathrm{sec}, T=300 \mathrm{~K}
$$

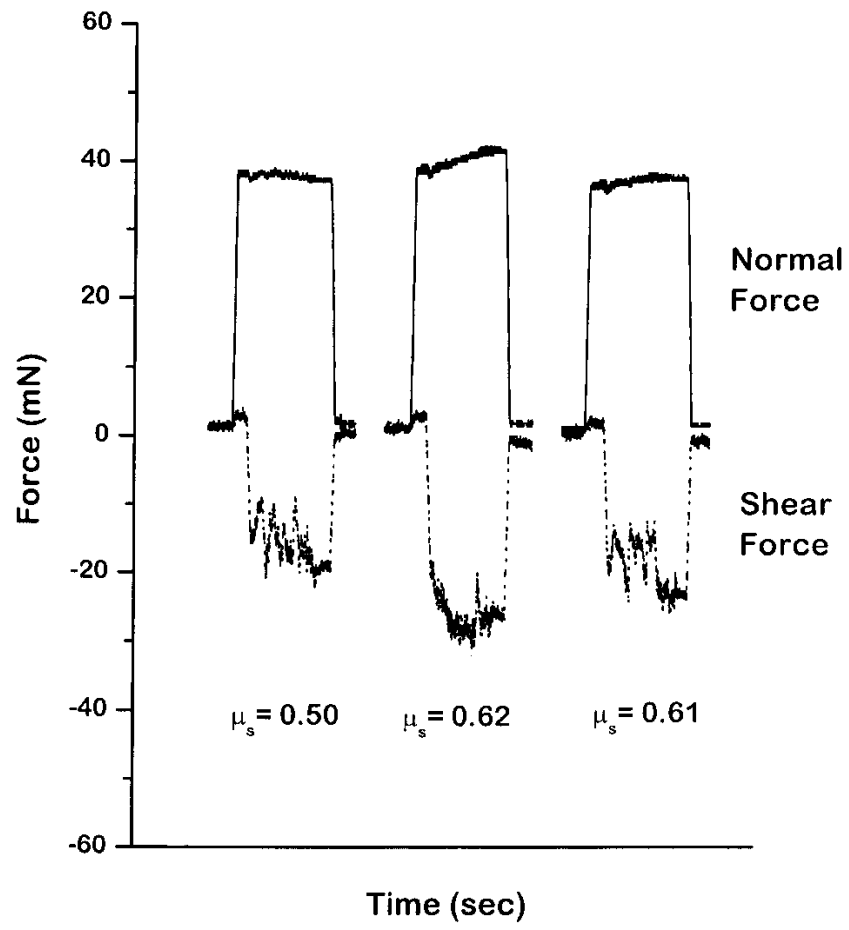

FIG. 4. Shear and normal forces observed during three friction measurements made between clean $\mathrm{Al}_{70} \mathrm{Pd}_{21} \mathrm{Mn}_{9}$ quasicrystal surfaces. The upper trace is a plot of the normal force, while the lower trace is a plot of the shear force. Friction behavior between the quasicrystals was found to be more regular and consistent than that observed between the approximants. No adhesion or stick-slip behavior was observed. The conditions used for friction measurements were $F_{\mathrm{N}} \sim 20-50 \mathrm{mN}, v_{\mathrm{s}}=20 \mu \mathrm{m} / \mathrm{s}$, and $T=300 \mathrm{~K}$. friction coefficient from $\mu_{\mathrm{s}}=1.22 \pm 0.85$ to $\mu_{\mathrm{s}}=0.83$ \pm 0.32 . Further oxidation by exposure to $\mathrm{H}_{2} \mathrm{O}$ vapor does not have a significant effect on the friction, which reaches $\mu_{\mathrm{s}}=0.71 \pm 0.20$. Oxidation causes a similar reduction in the friction of the quasicrystals from $\mu_{\mathrm{s}}=$ $0.60 \pm 0.08$ for the clean surfaces to a value of $\mu_{\mathrm{s}}=0.44$ \pm 0.04 following oxygen exposure alone and, finally, to $\mu_{\mathrm{s}}=0.35 \pm 0.05$ following exposure to $\mathrm{H}_{2} \mathrm{O}$ vapor.

The results of our friction measurements suggest that quasicrystallinity indeed influences friction since the approximant is seen to exhibit higher friction. Whether or not this is directly determined by the aperiodic versus periodic structures of the two surfaces is still not clear. For one thing it is important to keep in mind that the compositions of the quasicrystal and the approximant are different. In addition there are likely to be other materials properties such as bulk modulus or hardness that might influence friction and will differ between the two

\section{Friction vs. Oxidation} AIPdMn QC \& Approximant

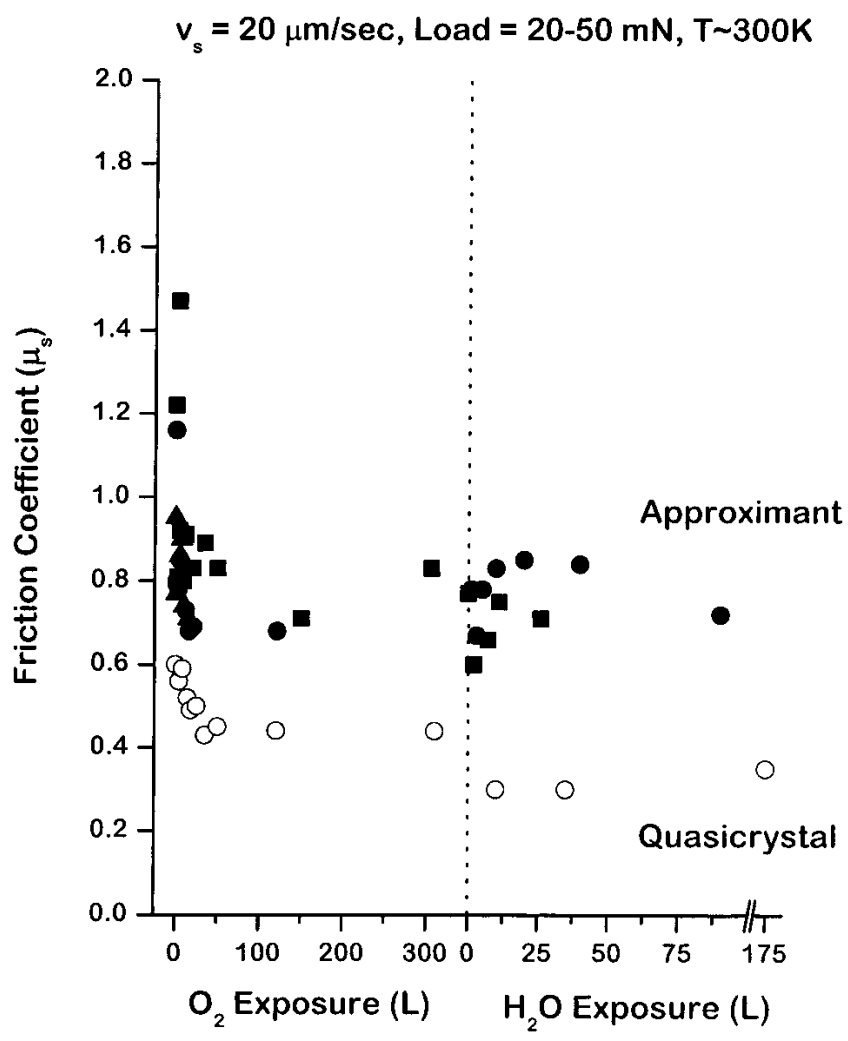

FIG. 5. Static friction coefficients measured between the surfaces of pairs of $\mathrm{Al}_{48} \mathrm{Pd}_{42} \mathrm{Mn}_{10}$ approximants (filled symbols) and between pairs of $\mathrm{Al}_{70} \mathrm{Pd}_{21} \mathrm{Mn}_{9}$ quasicrystals (open circles) as a function of surface oxidation. For both samples the friction coefficients are reduced by oxidation. At all levels of oxidation the friction between the $\mathrm{Al}_{70} \mathrm{Pd}_{21} \mathrm{Mn}_{9}$ quasicrystal surfaces is lower than that measured between the surfaces of the $\mathrm{Al}_{48} \mathrm{Pd}_{42} \mathrm{Mn}_{10}$ approximant. The conditions used for the friction measurements were $F_{\mathrm{N}}=40 \mathrm{mN}, v_{\mathrm{s}}=20 \mu \mathrm{m} / \mathrm{s}$, and $T=300 \mathrm{~K}$. 
samples. One observation which sheds some light on this comes from friction measurements performed previously between the $\mathrm{Al}_{70} \mathrm{Pd}_{21} \mathrm{Mn}_{9}$ quasicrystals which had been modified through annealing to form a "pseudotenfold" surface. The pseudotenfold surface has been shown to be a thin film alloy having the $\mathrm{CsCl}$ structure of the $\mathrm{Al}_{48} \mathrm{Pd}_{42} \mathrm{Mn}_{10}$ approximant. ${ }^{42}$ Like the approximant this surface alloy is Pd-rich with respect to the quasicrystal with an estimated stoichiometry of $\mathrm{Al}_{63 \pm 3} \mathrm{Pd}_{33 \pm 2} \mathrm{Mn}_{4 \pm 2}$. Friction measurements between quasicrystalline surfaces modified to form pseudotenfold surfaces revealed that such changes did not have any significant influence on their frictional properties. ${ }^{36}$ This suggests that bulk properties are perhaps responsible for the differences that we have observed in this direct comparison of the quasicrystal and approximant surfaces.

\section{Hardness}

Hardness $(H)$ can be an important factor in determining the friction between solids. Hardness is generally understood to be the resistance to local deformation as measured by forcing an indenter of some specific geometry into a free surface under a defined load. It is not a fundamental material property but rather a complex combination of properties such as elastic deformation, yield strength, ductility, work-hardening, and others. ${ }^{43}$ When two plastically deformable materials are brought into contact under some load or normal force $\left(F_{\mathrm{N}}\right)$ the contact area $(A)$ is given by

$$
A=\frac{F_{\mathrm{N}}}{H} .
$$

When the two surfaces are sheared relative to one another the force needed to shear the two $\left(F_{\mathrm{s}}\right)$ can be given as

$$
F_{\mathrm{s}}=\sigma A,
$$

where $\sigma$ is the shear yield strength of the interface. Under these conditions the coefficient of friction would be given by ${ }^{44,45}$

$$
\mu=\frac{F_{\mathrm{S}}}{F_{\mathrm{N}}}=\frac{\sigma}{H}
$$

For a lubricated interface with a shear strength that is independent of hardness, the friction coefficient depends inversely on hardness. Thus, it is easy to see how the low friction measured between air-exposed quasicrystal surfaces might be a result of high hardness. On the other hand, for an interface between truly clean surfaces of the same metal one might expect that the shear yield strength, $\sigma$, is directly related to the hardness, $H$. In the absence of adsorbed films, the coefficient of friction would be independent of hardness.

Reported values for the measured hardness of quasicrystals are in the range 6-10 GPa. ${ }^{1-5,46}$ We have measured the hardness of the quasicrystal and approximant samples used in this work. Microhardness measurements using a Vickers indenter gave average values of $7.8 \mathrm{GPa}$ for the $\mathrm{Al}_{70} \mathrm{Pd}_{21} \mathrm{Mn}_{9}$ quasicrystals and $2.6 \mathrm{GPa}$ for the $\mathrm{Al}_{48} \mathrm{Pd}_{42} \mathrm{Mn}_{10}$ approximants. Figure 6 shows the friction coefficients measured between clean surfaces of a number of materials using our UHV tribometer as a function of the hardness of each material. ${ }^{36,37,47-49}$ While the hardness of the quasicrystal and approximant samples were measured, reported values were used for the other materials. ${ }^{46,50-52}$ Figure 6 reveals a correlation between the hardness and the static coefficients of friction and suggests that hardness may be the root cause of the low friction of the quasicrystals. It should be noted that this figure hides some known phenomena such as the fact that the friction between the crystalline surfaces of metals can depend on their relative orientations. This has been observed using interfaces between $\mathrm{Ni}(100)$ surfaces and

\section{Static Friction Coefficients: Quasicrystal, Approximant, and Clean Metal Surfaces}

$v_{s}=20 \mu \mathrm{m} / \mathrm{sec}$, Load $=20-50 \mathrm{mN}, \mathrm{T}=300 \mathrm{~K}$



FIG. 6. Static friction coefficients measured between various clean metals and alloys as a function of Vicker's hardness numbers. Hardness values of the quasicrystal and approximant were measured directly while the hardness values for the metals were taken from literature. All friction coefficients were measured directly using the same instrumentation. The conditions used for friction measurements were $F_{\mathrm{N}} \sim 20-50 \mathrm{mN}, v_{\mathrm{s}}=20 \mu \mathrm{m} / \mathrm{s}$, and $T=300 \mathrm{~K}$. 
between Pd(100) surfaces. ${ }^{49,53}$ Nonetheless this does not distort the basic trend illustrated by Fig. 6 among the friction coefficients measured at interfaces between clean surfaces using our UHV tribometer.

The arguments made earlier suggest that for interfaces between clean metal surfaces where the critical shear yield strength is directly related to the hardness there should not be any relationship between friction and hardness. It is important to note though that the interface between two identical single crystal surfaces will never be a simple extension of the bulk of one sample into the bulk of the other. For one thing the two crystal orientations cannot match perfectly, and the interface will always represent a defect plane or grain boundary between the two bulk solids. Second, the plastic deformation that occurs during the formation of the contact between the two surfaces under macroscopic loads certainly dictates that the structure of the interfacial region is not a simple extension of the bulk crystal lattice. As a result the interface can have a shear yield strength that is not related to the hardness of the bulk crystal in any simple manner. Hence, while it would be enticing to say that the low friction of quasicrystals is due to quasicrystallinity itself, the data obtained to date and illustrated in Fig. 6 suggest that the hardness of the quasicrystals may be an important factor in determining their friction.

\section{CONCLUSIONS}

Using UHV tribometry and surface science methods, we have been able to measure the friction coefficient between pairs of truly clean $\mathrm{Al}_{48} \mathrm{Pd}_{42} \mathrm{Mn}_{10}$ approximant surfaces and compare it to the friction between pairs of truly clean $\mathrm{Al}_{70} \mathrm{Pd}_{21} \mathrm{Mn}_{9}$ quasicrystal surfaces. While the friction between quasicrystals was predominantly slip in nature, friction between the approximants was much more erratic with several instances of stick-slip friction and adhesion. Most importantly, the friction coefficient between the approximant surfaces was found to be twice as high as that between the quasicrystals.

The effect of oxidation on the properties of the approximants was also determined through exposure of the surfaces to $\mathrm{O}_{2}$ and then to $\mathrm{H}_{2} \mathrm{O}$ vapor under well-controlled UHV conditions. The first interesting observation was that the rate of oxidation of the quasicrystalline surface is roughly one order of magnitude lower than that of its approximant counterpart. This observation corroborates previous findings that quasicrystals exhibit some resistance to surface oxidation. ${ }^{6-9,11-14,38,39}$ Exposure to oxygen acted to passivate the surfaces and decrease the friction coefficient from $\mu_{\mathrm{s}}=1.22 \pm 0.85$ for the clean surfaces to $\mu_{\mathrm{s}}=0.83 \pm 0.32$ for the surfaces exposed to oxygen alone. Further oxidation through exposure to $\mathrm{H}_{2} \mathrm{O}$ vapor did not cause significant further reduction in the friction.
The quasicrystals were previously found to exhibit the same general behavior, but for all degrees of oxidation the friction between quasicrystals was roughly half that of the approximants. Friction measurements between air contaminated surfaces yielded even lower friction coefficients of $\mu_{\mathrm{s}}=0.10 \pm 0.02$ for the approximants and $\mu_{\mathrm{s}}=0.11 \pm 0.02$ for the quasicrystals. It is clear that oxidation, at least to the level possible under UHV conditions, is not the only contributor to the low friction observed for quasicrystals in air. Finally, it is important to point out that the hardness of the $\mathrm{Al}_{70} \mathrm{Pd}_{21} \mathrm{Mn}_{9}$ quasicrystals was found to be greater than that of the $\mathrm{Al}_{48} \mathrm{Pd}_{42} \mathrm{Mn}_{10}$ approximants. This is somewhat disappointing in the sense that, in the quest to elucidate whether quasicrystallinity itself is the major cause of low friction in these materials, we would like to analyze samples with similar bulk properties yet different bulk structure. Hardness itself, however, is influenced by bulk structure and thus quasicrystallinity may influence friction through bulk hardness rather than aperiodicity of the surface structure.

These experiments reveal that there are substantial differences between two alloys of similar composition but differing in that one has a crystalline structure while the other is quasicrystalline. This work gives some insight into the relationships between the surface and bulk mechanical properties of the quasicrystals and the possible origins of their unique properties. To categorically pin down the relationship of these properties to structure, however, it is necessary to use an extensive set of samples spanning a range of compositions that lie within and around the quasicrystalline region of the compositional phase diagram of these alloys.

\section{ACKNOWLEDGMENTS}

This work was supported by the Director, Office of Energy Research, Office of Basic Energy Sciences, Material Sciences Division, of the United States Department of Energy under Contract No. W-405-Eng-82, and instrumentation was developed with support from the Air Force Office of Scientific Research under Grant No. AFOSR F49620-01-1-0069.

\section{REFERENCES}

1. S.S. Kang, J.M. Dubois, and J. von Stebut, J. Mater. Res. 8, 2471 (1993).

2. J.M. Dubois, S.S. Kang, and A. Perrot, Mater. Sci. Eng. A179/ A180, 122 (1994).

3. R. Wittmann, K. Urban, M. Schandl, and E. Hornbogen, J. Mater. Res. 6, 1165 (1991).

4. J.M. Dubois, S.S. Kang, and J. von Stebut, J. Mat. Sci. Lett. 10, 537 (1991).

5. J. von Stebut, J.M. Soro, P. Plaindoux, and J.M. Dubois, in New Horizons in Quasicrystals Research and Applications, edited by A.I. Goldman, D.J. Sordelet, P.A. Thiel, and J.M. Dubois (World Scientific Publishing, Singapore, 1997), p. 248. 
6. M. Gavatz, D. Rouxel, P. Pigeat, B. Weber, and J.M. Dubois, Philos. Mag. A 80, 2083 (2000).

7. P.J. Pinhero, J.W. Anderegg, D.J. Sordelet, M.F. Besser, and P.A. Thiel, Philos. Mag. B 79, 91 (1999).

8. P.J. Pinhero, D.J. Sordelet, J.W. Anderegg, P. Brunet, J.M. Dubois, and P.A. Thiel, in Quasicrystals, edited by J.M. Dubois, P.A. Thiel, A.P. Tsai, and K. Urban (Mater. Res. Soc. Symp. Proc. 553, Warrendale, PA, 1999), p. 263.

9. B.I. Wehner and U. Köster, in Quasicrystals, edited by J.M. Dubois, P.A. Thiel, A.P. Tsai, and K. Urban (Mater. Res. Soc. Symp. Proc. 553, Warrendale, PA, 1999), p. 269.

10. B.I. Wehner, U. Köster, A. Rüdiger, C. Pieper, and D.J. Sordelet, Mater. Sci. Eng. 294-296, 830 (2000).

11. C.J. Jenks, P.J. Pinhero, S.L. Chang, J.W. Anderegg, M.F. Besser, D.J. Sordelet, and P.A. Thiel, in New Horizons in Quasicrystal Research and Applications, edited by A.I. Goldman, D.J. Sordelet, P.A. Thiel, and J.M. Dubois (World Scientific Publishing, Singapore, 1997), p. 157.

12. B.I. Wehner, and U. Köster, in New Horizons in Quasicrystals Research and Applications, edited by A.I. Goldman, D.J. Sordelet, P.A. Thiel, and J.M. Dubois (World Scientific Publishing, Singapore, 1997), p. 152.

13. D. Rouxel, M. Gavatz, P. Pigeat, B. Weber, and P. Plaindoux, in New Horizons in Quasicrystal Research, edited by A.I. Goldman, D.J. Sordelet, P.A. Thiel, and J.M. Dubois (World Scientific Publishing, Singapore, 1997), p. 173.

14. S.L. Chang, J.W. Anderegg, and P.A. Thiel, J. Non-Cryst. Solids 195, 95 (1996).

15. P. Sainfort and B. Dubost, in Quasicrystalline Materials, edited by C. Janot and J.M. Dubois (World Scientific Publishing, Singapore, 1988), p. 361.

16. J.M. Dubois, S.S. Kang, P. Archambault, and B. Colleret, J. Mater. Res. 8, 38 (1993).

17. P. Archambault and C. Janot, MRS Bull. 48 (November 1997).

18. E. Belin-Ferre, in Quasicrystals, edited by J.M. Dubois, P.A. Thiel, A.P. Tsai, and K. Urban (Mater. Res. Soc. Symp. Proc. 553, Warrendale, PA, 1999), p. 347.

19. L.M. Zhang, C. Dong, P. Brunet, and J.M. Dubois, Mater. Sci. Eng. 294-296, 810 (2000).

20. C. Dong, J. Wu, L.M. Zhang, J.M. Dubois, P. Brunet, Q.G. Zhou, D. Wang, and H.C. Zhang, in Quasicrystals: Preparation, Properties and Applications, edited by E. Belin-Ferre, P.A. Thiel, A.P. Tsai, and K. Urban (Mat. Res. Soc. Symp. Proc. 643, Warrendale, PA, 2001), p. K7.5.1.

21. C. Dong, A. Perrot, J.M. Dubois, and E. Belin-Ferre, Mater. Sci. Forum 150-151, 403 (1994).

22. C. Dong, Scr. Metall. Mater. 33, 239 (1995).

23. F. Lancon, Europhys. Lett. 57, 74 (2002).

24. F. Lancon, J.M. Penisson, and U. Dahmen, Europhys. Lett. 49, 603 (2000).

25. G. He, M.H. Muser, and M.O. Robbins, Science 284, 1650 (1999).

26. E. Rajasekaran, X.C. Zeng, and D.J. Diestler, in Micro/ Nanotribology and Its Applications, edited by B. Bhushan (Kluwer Academic Publishers, Dordrecht, The Netherlands, 1997), p. 371.

27. I.L. Singer, J.M. Dubois, J.M. Soro, D. Rouxel, and J. von Stebut, in Quasicrystals, edited by S. Takeuchi and T. Fujiwara (Proc. 6th Intl. Conf. on Quasicrystals, Singapore, 1998), p. 769.
28. L.M. Zhang, H.C. Zhang, Q.G. Zhou, and C. Dong, Wear 225-229, 784 (1999).

29. C. Dong, L.M. Zhang, E. Belin-Ferre, P. Brunet, and J.M. Dubois, Mater. Sci. Eng. A 304-306, 172 (2001).

30. J.M. Dubois, P. Brunet, and E. Belin-Ferre, in Current Topics on Quasicrystals, edited by E. Belin-Ferre, C. Berger, M. Quiquandon, and A. Sadoc (World Scientific, Singapore, 2000), p. 499.

31. B. Grushko, M. Yurechko, and N. Tamura, J. Alloys Compd. 290, 164 (1999).

32. T. Gødecke and R. Lòck, Z. Metallkd. 86, 109 (1995).

33. M. Audier, M. Durand-Charre, and M. de Boissieu, Philos. Mag. B 68, 607 (1993).

34. M. Quiquandon, Y. Calvayrac, A. Quivy, F. Faudot, and D. Gratias, in Quasicrystals, edited by J.M. Dubois, P.A. Thiel, A.P. Tsai, and K. Urban (Mater. Res. Soc. Symp. Proc. 553, Warrendale, PA, 1999), p. 95.

35. C. Dong, D.H. Wang, Y.M. Wang, F. Ge, F.Z. He, Q.H. Zhang, K. Chattopadhyay, and S. Ranganathan, in Quasicrystals, edited by S. Takeuchi and T. Fujiwara (World Scientific, Singapore, 1997), p. 223.

36. J.S. Ko, A.J. Gellman, C. Jenks, T. Lograsso, and P.A. Thiel, Surf. Sci. 423, 243 (1999).

37. A.J. Gellman, J. Vac. Sci. Technol. A 10, 180 (1992).

38. S.S. Kang and J.M. Dubois, J. Mater. Res. 10, 1071 (1995).

39. P.A. Thiel, A.I. Goldman, and C. Jenks, in Physical Properties of Quasicrystals, edited by Z.M. Stadnik (Springer, New York, 1999), p. 327.

40. C. Jenks, P.J. Pinhero, T.E. Bloomer, J. W. Anderegg, and P.A. Thiel, in Quasicrystals, edited by S. Takeuchi and T. Fujiwara (World Scientific, Singapore, 1998), p. 761.

41. M. Gavatz, D. Rouxel, D. Claudel, P. Pigeat, and B. Weber, in Quasicrystals, edited by T. Fujiwara (World Scientific, Singapore, 1998), p. 765.

42. Z. Shen, M.J. Kramer, C.J. Jenks, A.I. Goldman, T. Lograsso, D. Delaney, M. Heinzig, W. Raberg, and P.A. Thiel, Phys. Rev. B 58, 9961 (1998).

43. C.J. McHargue, in Micro/Nanotribology and its Applications, edited by B. Bhushan (Kluwer Academic Publishers, Dordrecht, Netherlands, 1997), p. 467.

44. F.P. Bowden and D. Tabor, The Friction and Lubrication of Solids (Clarendon Press, Oxford, U.K., 1986).

45. J. Larsen-Basse, in ASM Handbook, edited by P.J. Blau (ASM International, Materials Park, OH, 1992), p. 27.

46. A.P. Tsai, H. Suenaga, M. Ohmori, Y. Yokoyama, A. Inque, and T. Masumoto, Jpn. J. Appl. Phys. 31, 2530 (1992).

47. C.F. McFadden, Ph.D. Thesis, University of Illinois (1996).

48. C.F. McFadden and A.J. Gellman, Langmuir 11, 273 (1995).

49. J.S. Ko and A.J. Gellman, Langmuir 16, 8343 (2000).

50. H. O'Neill, Hardness Measurement of Metal and Alloys (Chapman and Hall, London, U.K., 1967).

51. H.E. Boyer and T.L. Gall, Metals Handbook (American Society of Metals, Metals Park, OH, 1985).

52. D. Tabor, The Hardness of Metals (Clarendon Press, Oxford, U.K., 1951).

53. C.M. Mancinelli and A.J. Gellman (unpublished results). 